\title{
GEORGES DUHAMEL E A CONSTRUÇÃO DA NARRATIVA COM SUAS MEMÓRIAS IMAGINÁRIAS
}

\author{
GEORGES DUHAMEL AND THE CONSTRUCTION OF THE NARRATIVE WITH HIS IMAGINARY \\ MEMORIES
}

\author{
Daniela Mantarro CALLIPO \\ Universidade Estadual Paulista Júlio de Mesquita Filho \\ danielacallipo@gmail.com \\ Mariana Mansano CASONI \\ Universidade Estadual Paulista \\ mari_casoni@hotmail.com
}

\begin{abstract}
Resumo: Apesar de ser um escritor pouco estudado, o francês Georges Duhamel (1844-1966) apresenta uma vasta bibliografia, suas obras passam por vários gêneros como a poesia, romances e ensaios. Este artigo tem como objetivo evidenciar seu lado crítico, bem como apresentar seu pensamento em relação à construção literária, sobretudo ao romance, principalmente o que ele denomina de memórias imaginárias, a qual seria a chave para a recriação do real e, consequentemente, traria o conhecimento da verdade. A partir da literatura comparada, é possível estabelecer pontos divergentes e convergentes entre sua obra Remarques sur les mémoires imaginaires (1933) e Du côté de chez Swann (1913) de Marcel Proust, no que se refere à busca pela verdade. Para ambos os autores, a verdade advém do sofrimento, no entanto, o mecanismo para chegar até ela se difere em suas obras, já que para Duhamel as memórias devem ser inventadas e não restituídas, visto que elas carregam paixões que as adulteram, enquanto que para Proust a verdade vem por meio do acaso e estão contidas nos objetos. A experiência do sofrimento vivido na Primeira Guerra Mundial trouxe a Duhamel um olhar diferenciado as suas narrativas, ele pôde, assim, transmitir suas experiências de vida de um modo não particular, mas universal, tentando sempre revelar a verdade a partir da ficção.
\end{abstract}

Palavras-chave: George Duhamel. Construção da narrativa. Memórias imaginárias.

Abstract: Despite being a poorly studied writer Georges Duhamel (1844-1966) presents a vast bibliography, his works go through various genres such as poetry, novels and essays. This article aims to highlight its critical side, as well as present its thinking in relation to literary construction, especially to the novel, especially what he calls imaginary memories, which would be the key to the re - creation of the real and, consequently, would bring knowledge of truth. From the comparative literature, it is possible to establish divergent and convergent points between his work Remarques sur les mémoires imaginaires (1933) and Du côté de chez Swann (1913) by Marcel Proust, in what concerns the search for truth. For both authors, truth comes from 
suffering, however, the mechanism to reach it differs in their works, since for Duhamel the memories must be invented and not restituted, since they carry passions that adulterate them, whereas for Proust the truth comes by chance and is contained in objects. The experience of suffering experienced in World War brought Duhamel a different look at his narratives, he was able to thus transmit his life experiences in a non-particular but universal way, always trying to reveal the truth from fiction.

Key-words: George Duhamel. Construction of the narrative. Imaginary memories

\section{Georges Duhamel: da guerra à literatura}

O século XIX revelou grandes destaques na literatura francesa como Victor Hugo, Gustave Flaubert, Marcel Proust, entre outros que permaneceram no cânone da literatura. No entanto, outros escritores também tiveram destaque com suas obras, mas que no decorrer das décadas ficaram esquecidos. Este é o caso do escritor francês, nascido em Paris, Georges Duhamel (1884-1966), que inicia sua carreira médica juntamente com seus estudos literários.

Sua carreira literária efetiva-se a princípio com a poesia, já no início do século XX ele contribui com o jornal Mercure de France e, após atuar como médico cirurgião na Primeira Guerra Mundial, ele abandona a medicina e passa a dedicar-se integralmente às Letras. É neste período que sua obra de cunho humanista se evidencia com La possession du monde (1919) e Scènes de la vie future (1930), no entanto tem sua maior consagração e reconhecimento com Vie et Aventures de Salavin (1927) e Chronique des Pasquier (1933), aquela com seis volumes e esta com dez volumes.

Após servir na guerra, tem sua vida transformada pela experiência de ver o sofrimento de perto, do resultado desta experiência nasce a obra Civilisation, ganhadora do prêmio literário francês Goncourt, em 1918. Autor de uma extensa produção literária, suas principais obras são voltadas às questões inerentes ao homem, como questões existenciais permeadas pelo ceticismo, principalmente Vie et Aventures de Salavin (1927) e Chronique des Pasquier (1933) esta considerada obra de sua fase madura, na qual narra a história de uma família burguesa entre os anos de 1880 e 1930.

Sabe-se que por volta de 1830, o Parnasianismo começou com suas primeiras expressões, neste período havia uma preocupação dos escritores em melhorar a condição humana e de colocar a palavra a serviço do progresso social. É também 
neste momento em que a expressão "arte pela arte" surge. Ao que tudo indica Victor Hugo foi o precursor desta frase ao proferi-la em seu prefácio na obra Orientales, ao defender o direito do poeta de escrever "um livro inútil de pura poesia" (TIEGHEM, 1957, p.235).

É no período literário do Parnasianismo que Georges Duhamel inicia seus estudos literários e, no início do século XX, começa a publicar suas obras. Seus romances, entretanto, destoam da característica principal do Parnasianismo: a rejeição às questões social, moral e política, visto que suas obras são marcadas pela crítica.

O período entre guerras foi o mais marcante para o escritor francês, como já mencionado, ele foi decisivo para sua carreira, pois abandona a medicina e passa então a dedicar-se integralmente à literatura. Seu posicionamento como escritor neste período encontra-se entre a literatura militante e a "desengajada", segundo Benoît Denis em Literatura e engajamento: de Pascal a Sartre (2002), este "desengajado" seria na verdade o autêntico escritor social. Este conceito liga-se ao de Roland Barthes, pois para ele a

(...) escritura é valor, ela é o lugar específico onde o escritor se engaja e assume suas responsabilidades pela escolha de uma certa forma, disponível entre as possibilidades literárias existentes (DENIS, 2002, p.293-4).

É possível observar este "desengajamento" na obra Scènes de la vie future (1930) considerada extremamente crítica e que quase beira o panfletário, na qual o escritor francês tem como alvo a "civilização das máquinas", bem como a possível americanização da Europa.

Observando a trajetória deste escritor, fica evidente de que ele não só era reconhecido em seu país de origem, como também no Brasil, visto que suas obras lançadas eram divulgadas nos principais jornais do país, bem como suas visitas constantes à terra de Machado de Assis. É possível comprovar este reconhecimento por meio dos jornais brasileiros, como por exemplo, o Correio da Manhã do Rio de Janeiro, do dia 19 de novembro de 1932 que apresenta uma manchete na qual encontra-se a seguinte chamada: "Seis escritores franceses se dirigem em cativantes mensagens aos escritores brasileiros" (p.01), dentre os escritores citados, Georges Duhamel estava presente a fim de motivar os escritores brasileiros a preservar a cultura latina. 


\section{Da França para o Brasil}

Como dito anteriormente, o nome de Georges Duhamel circulava entre os principais jornais do Brasil antes de cair no esquecimento. Além disso, é preciso lembrar a estreita ligação entre Brasil e França em várias esferas, sobretudo a literária. Sabe-se que a língua francesa era comum aos escritores brasileiros e que estes liam as obras tanto dos autores célebres, quanto as de seus contemporâneos. $E$ isto não foi diferente ao escritor mineiro Cyro dos Anjos, autor de O amanuense Belmiro (1937), Abdias (1945), Montanha (1956), entre outras obras.

Em sua obra de estreia, O amanuense Belmiro (1937), o autor mineiro abre seu romance com duas epígrafes de Georges Duhamel. As duas epígrafes são da pequena obra Remarques sur les mémoires imaginaires, publicada em 1933, na qual, como o título revela, tratam-se de apontamentos sobre memórias, no entanto, não quaisquer memórias, mas as imaginárias. A obra, composta de 32 capítulos breves, apresenta várias críticas ao fazer literário e, é iniciada com a seguinte a afirmação: "Eu não escreverei minhas memórias" (DUHAMEL, 1934, p.07), esta primeira frase de Duhamel já deixa claro para o leitor que a obra não se trata de uma narrativa memorialística, muito menos biográfica. Também por esta negativa é possível prever o tom crítico do autor francês.

As duas epígrafes, que dão início à obra do autor brasileiro, referem-se justamente à questão da memória: "As lembranças que tenho de minha vida real não são mais coloridas nem mais vibrantes que estas de minhas vidas imaginárias"1 (tradução nossa) e

Para escrever a história de um outro, eu colaboro com minha própria vida. Que não se busque saber quem, nesta ficção, sou eu, sem dúvidas. Sobre isto se enganariam. E os meus próximos se enganariam mais do que os outros ${ }^{2}$ (tradução nossa).

Elas resgatam a questão central presente na obra do autor francês: a criação e a memória, elementos também presentes na obra brasileira. $O$ amanuense Belmiro, publicado em 1937, tem como protagonista Belmiro Borba, burocrata solteiro de 38

\footnotetext{
${ }^{1}$ «Les souvenirs que j'ai de ma vie réelle ne sont ni plus colorés ni plus vibrants que ceux de mes vies imaginaires » (ANJOS, 1975, p.03).

${ }^{2}$ « Pour écrire l'histoire d'un autre, je collabore avec ma propre vie. Qu'on ne cherche pas à savoir ce qui, dans cette fiction, est indubitablement moi. On s'y tromperait. Et mes proches s'y tromperaient autant et plus que les autres » (IDEM).
} 
anos, que narra os acontecimentos de sua vida e os de seus amigos. A narrativa se desenvolve em primeira pessoa e o tom lírico garante a leveza da linguagem.

Cyro, ao inserir dois trechos da obra do autor francês, não quer senão alertar o leitor para o fato de que, mesmo tratando-se de memórias, não são autobiográficas, assim deixa claro sua intenção: a de tecer memórias imaginárias, como Duhamel. Cyro publica sua obra de cunho aparentemente intimista em uma época em que a experimentação da linguagem estava em alta no Brasil com o modernismo, no entanto o autor mineiro faz sua experimentação a partir do "travestimento" de sua obra, ou seja, a modernidade de sua obra não se mostra por meio de sua linguagem, mas está presente nas camadas da narrativa, nas quais é possível observar, a partir de uma análise atenta, a reflexão de questões importantes, como o papel do intelectual na sociedade.

Este travestimento da obra ou este não se mostrar claramente é o tema abordado por Duhamel em Remarques sur les mémoires imaginaires (1933), pois há um conflito instaurado: o desejo de escrever romances por parte do autor, contra o desejo dos leitores pelas memórias e pelos fatos reais. A solução que ele encontra é chamar sua narrativa de memórias imaginárias, assim não deixaria de atrair os leitores para sua obra ao mesmo tempo que satisfaria seu desejo.

\section{Os comedores de carne crua versus os comedores de carne cozida}

Em Remarques sur les mémoires imaginaires (1933), Duhamel deixa claro seu ponto de vista a respeito dos movimentos de vanguarda, como o dadaísmo e o surrealismo. Nesta época os escritores do chamado roman d'analyse (romance intimista) criticaram as consequências trazidas por este movimento. Duhamel também não ficou de fora e a obra Remarques sur les mémoires imaginaires é considerada por alguns críticos, como João Luiz Lafetá, como uma reação tardia a estes movimentos. ${ }^{3}$

Uma das consequências que os movimentos de vanguarda trouxeram está presente em algumas obras de André Gide, segundo Silviano Santiago ele passa a ter interesse no papel do acaso na construção do romance, bem como na escrita a partir de faits divers, ou seja, acontecimentos do cotidiano citadino, triviais ou

\footnotetext{
${ }^{3}$ Ensaio intitulado 1930: a crítica e o modernismo, de 1974.
} 
criminosos, que muitas vezes eram motivo de escândalo. Sobre esta mudança na escritura de Gide, Duhamel o critica com relação a esta nova forma de compor o romance, o escritor francês utiliza a expressão "comedores de carne crua" para se referir aos escritores que privilegiavam a reprodução do real.

\begin{abstract}
Em 1926, André Gide começou, na Nouvelle Revue Française, a publicação de uma crônica de faits divers. André Gide chama, simplesmente, "belo faits divers" uma narrativa "capaz de nos instruir, de nos ensinar o que há de novo na psicologia." Pode-se imaginar qual interesse, talvez mesmo qual esperança a carta inicial de Gide deve ter despertado nos amadores do fato puro, a estes eu chamo, sem a menor ironia, de comedores de carne crua. ${ }^{4}$ (tradução nossa).
\end{abstract}

Portanto, para Duhamel, autores que escrevem suas obras reproduzindo os fatos tal como eles se apresentam seriam "comedores de carne crua", já que a escrita não passaria por nenhum processo de criação que a obra de arte exigiria. Esta tendência, de narrar fatos da vida cotidiana sem apresentar elementos ficcionais, resvala na questão da memória, tema tratado em sua obra Remarques sur les mémoires imaginaires (1933). Segundo Duhamel, os leitores têm mais interesse pelas obras memorialísticas e/ou biográficas às ficcionais, para ele um exemplo claro dessa preferência se mostra por meio da epopeia, estas narrativas de feitos homéricos que se perderam ao longo do tempo, uma das únicas que permanece no rol das obras clássicas é $A$ llíada.

Ao longo de sua carreira como escritor, ele pôde observar a confusão que os leitores fazem em relação a primeira pessoa do singular. Geralmente, os leitores atribuem as características do narrador em primeira pessoa ao escritor. Sobre isto Philippe Lejeune em Le pacte autobiographique (1975) discorre que o fato de a narrativa ser escrita em primeira pessoa não significa que seja uma obra autobiográfica. Lejeune afirma existir um pacto romanesco entre o autor e o escritor, neste pacto ficcional o leitor deve estar consciente de que os fatos narrados se referem ao narrador e não ao escritor da obra. Segundo o autor francês, haveria uma forma do leitor diferenciar uma obra autobiográfica de uma ficcional, quando o nome do

\footnotetext{
${ }^{4}$ «En 1926, André Gide a commencé, dans la Nouvelle Revue Française, la publication d'une chronique de faits divers. André Gide appelle, fort justement, ' beau faits divers' un récit 'capable de nous instruire, de nous apprendre quoi que ce soit de neuf en psycologie.' On imagine quel intérêt, peut-être meme quelle espérance la lettre initiale de Gide a dû susciter chez les amateurs de fait pur, chez ceux que j'appelle, sans la moindre ironie, les mangeurs de chair crue. » (DUHAMEL, 1934, p,18)
} 
narrador-personagem for diferente do nome do autor da obra, entende-se que há uma ficção, um pacto romanesco:

Somente este fato exclui a possibilidade da autobiografia (...). Que a história seja apresentada como verdadeira ou que ela seja apresentada como fictícia - de qualquer maneira, não há identidade do autor, do narrador e do herói. ${ }^{5}$ (tradução nossa)

Evidente que isto também poderia levar ao leitor ao equívoco, assim a forma mais acertada seria a do leitor esquecer a figura do escritor durante a leitura. Duhamel após estas constatações passa então a travestir sua narrativa, a faz de modo que aparentemente seja de cunho memorialista, mas que na verdade é pura ficção. Esta foi a sua estratégia para ganhar aqueles leitores que preferem ler memórias. É, portanto, esta discussão que ele, ao escrever Remarques sur les mémoires imaginaires, quer salientar e expor seu ponto de vista.

\section{A recriação do real}

Duhamel acredita que o escritor ao simplesmente transpor uma realidade para o papel não está criando uma obra de arte, visto que esta imagem do real deve apresentar certo polimento artístico. Tanto os fatos da realidade alheias ao escritor, quanto os que compõem sua vida (as memórias), não revelam a beleza da verdade: "Qual meio nos é dado de conhecer a realidade, de nos amparar nesta presa insaciável? É preciso recriar o real"6 (tradução nossa). Assim a verdade só seria conhecida por meio da recriação do real, já que ao colocar no papel as lembranças vividas elas representarão somente uma pequena parcela daquilo que realmente foi vivido.

Há, para o autor francês, uma contradição instaurada, pois mesmo que haja documentos, como por exemplo, correspondências, elas nunca mostrarão as lembranças vividas internamente pelo sujeito, suas reais emoções e seus pensamentos. Portanto, os fatos externos raramente coincidem com aquilo que se viveu internamente.

\footnotetext{
${ }^{5}$ Ce seul fait exclut la possibilité de l'autobiographique. Que l'histoire soit présentée comme vraie ou qu'elle soit présentée comme fictive - de toute façon, il n'y a pas identité de l'auteur, du narrateur et du héros . (LEJEUNE, 1975, p.28-29)

${ }^{6}$ «Quel moyen nous est donné de connaître la réalité, de nous emparer de cette proie insaisissable? Il faut recréer le réel » (DUHAMEL, 1934, p.49).
} 
Duhamel em sua obra escreve uma espécie de manifesto contra a escrita de memórias, entende-se por memórias a narrativa que se baseia em fatos puros. Ao longo de sua pequena obra, escrita em primeira pessoa, a frase "eu não escreverei minhas memórias" se repete como uma espécie de refrão na tentativa de não só demonstrar sua recusa a fazer este tipo de obra, mas também de salientar o tipo de obra que ele tem mais apreço e, com isso, defender a tese de que a verdade se manifesta na recriação do real e não em sua cópia.

Mesmo aqueles que afirmam escrever de modo fiel o fato ocorrido utilizam-se de vários recursos como o recorte, a supressão e a seleção das cenas. Para Duhamel narrar algo ocorrido não traz tanta beleza quanto narrar algo inventado. Assim, o escritor francês lança mão de uma estratégia eficaz, comprovada ao longo de sua carreira, para não se render à tendência de escrever memórias. Ao invés de escrever suas memórias ele escreve a de um outro, a de suas criaturas ficcionais.

Este travestimento de sua obra, a escrita de memórias que não são as suas, mas a de personagens fictícios lhe garantiu o sucesso de suas obras, por exemplo, Vie des Martyrs (1917) e Civilisation (1918), esta última Ihe rendeu o prêmio Goncourt em 1918. Obras estas que são memórias da Primeira Guerra, no entanto, mesmo servindo na guerra ele optou por narrar as memórias do sofrimento de maneira geral e não particular. Assim, mesmo vivenciando de perto o sofrimento, ele consegue distanciarse de si e passa a enxergar a dor como uma experiência coletiva e não individual.

Esta experiência do sofrimento lhe trouxe a oportunidade de por em prática a busca da verdade. "Eu compus, durante a guerra, um certo número de narrativas para afirmar o que me parecia então a única certeza incontestável, a única realidade perfeita, o sofrimento dos homens"7 (tradução nossa). Esta realidade do sofrimento e a busca da verdade pode ser também encontrada na célebre obra de Marcel Proust (1871-1922) La recherche du temps perdue (1913). Além da busca pelo passado, o protagonista anseia pela verdade, a qual desencadearia a descoberta de sua vocação literária.

A busca pela verdade do narrador proustiano ocorre em função de algo que o incomoda, de uma situação que o move para essa busca, como por exemplo, uma

\footnotetext{
${ }^{7}$ « J'ai composé, pendant la guerre, un certain nombre de récits pous affirmer ce qui me semblait alors la seule certitude indiscutable, l'unique réalité parfaite, la souffrance des hommes » (DUHAMEL, 1934, p.49-50).
} 
situação de sofrimento. Esse desejo, como explicita Giles Deleuze, não parte naturalmente de uma vontade pura do ser humano, mas de uma angústia, uma dor. É exatamente isto o que ocorre com o narrador ao longo de toda a obra; especificamente no primeiro capítulo "Combray", nota-se seu sofrimento em relação a sua vocação, ao desejo de se tornar um escritor, bem como seus conflitos.

Guardadas as devidas proporções na comparação entre o sofrimento que Duhamel viveu na guerra e o sofrimento do narrador proustiano, tem-se o mesmo mecanismo da busca pela verdade. Há algo, no entanto, que difere os dois, o narrador proustiano consegue alcançar a verdade graças ao acaso, ou seja, por meio de objetos presentes em seu cotidiano que o fazem rememorar seu passado, adquirindo, assim, uma grande importância, pois para o narrador possuem uma espécie de alma, de essência. O contato com o objeto torna Marcel capaz de resgatar o passado; sem este contato, o estopim da memória involuntária seria impossível. Sendo assim, por meio do retorno ao passado, o narrador consegue desenvolver a trajetória do aprendizado, bem como o desenvolvimento da descoberta de sua vocação, já que por meio da rememoração do passado, ele é capaz de escrevê-lo de modo detalhado e poético.

Como pode-se observar outra característica da obra de Proust é que a busca pela verdade está diretamente ligada à busca pelo passado do protagonista. Elemento que difere das obras de Duhamel, visto que para ele a verdade não está ligada ao passado. A verdade, portanto, estaria ligada à reconstrução do real, à ficção e à mistura daquilo que se viveu e daquilo que se cria "Que tudo esteja ligado, fundido, para a salvação da única verdade, a verdade humana"8. A verdade, portanto, só é obtida a partir da junção de vários elementos e não somente por meio da memória, pois ela adultera os acontecimentos, visto que está permeada pelas paixões e até mesmo pela arte.

Outro ponto divergente entre as obras dos escritores franceses está na forma, enquanto o narrador proustiano opta pela primeira pessoa o de Duhamel apresentase na terceira pessoa do singular. A estrutura de "Combray", primeiro capítulo de Du côté de chez Swann, se forma e se desenvolve em torno do "eu", que oferece ao leitor o ponto de vista do protagonista, ponto de vista este que procura ser a de um

\footnotetext{
${ }^{8}$ «Que tout soit lié, fondu, pour le salut de seule verité, la verité humaine » (DUHAMEL, 1934, p.64). 
observador imparcial, pois, por meio do tempo o narrador "modifica" seu olhar diante das diferentes situações da vida. Sabe-se, porém, que essa tentativa de imparcialidade é relativa, visto que o "je" usado por Proust caracteriza-se por ser subjetivo. $^{9}$

Proust apresenta em sua narrativa uma técnica bem peculiar e característica, organizando-a de acordo com o tempo, com os acontecimentos; desta maneira, ele os narra não obedecendo à ordem cronológica dos fatos, mas mistura os tempos presente e passado e algumas vezes até introduz personagens, cujas ações só serão conhecidas posteriormente.

Sobre as personagens, é interessante observar que muitas vezes elas representam ideologias do escritor. Esta questão ganha mais clareza quando elas são analisadas como um todo, desde seus nomes até seus comportamentos. Antonio Candido define a personagem como “(...) um ser fictício, isto é, algo que, sendo uma criação da fantasia, comunica a impressão da mais lídima verdade existencial" (CANDIDO, 1995, p. 55). A construção da personagem deve ocorrer de forma semelhante ao conhecimento que temos dos seres reais, conhecimento este que é fragmentário; portanto, o escritor "(...) nada mais faz do que retomar, no plano da técnica de caracterização, a maneira fragmentária, insatisfatória, incompleta, com que elaboramos o conhecimento dos nossos semelhantes" (IDEM).

A obra do autor francês se inicia com um narrador-personagem, que não revela sua identidade imediatamente, muito menos suas características físicas. É um narrador que apresenta traços emocionais e psicológicos bem explorados pelo autor. A maior parte das personagens de "Combray" não é caracterizada por meio de aspectos físicos, mas de suas ações, seus aspectos morais e psicológicos.

Portanto, o narrador proustiano ao retomar sua trajetória vivida no passado, se transporta no tempo, misturando presente e passado enquanto o narrador de Duhamel permanece no presente narrando os fatos das personagens. Nesta escrita do eu, presente na obra de Proust, as descrições das cenas são extremamente detalhadas o que leva uma certa lentidão na leitura, visto que as ações não são tão frequentes.

Observa-se assim dois estilos diferentes que apresentam o mesmo objetivo, o de buscar a verdade. Para um, a verdade está presente no passado e é desencadeada

\footnotetext{
${ }^{9}$ Benveniste, aliás, caracteriza o "je" como "personne subjective" (BENVENISTE, Problèmes de Linguistique Générale, Tome I, Paris: Gallimard, 2000, p. 32). 
pelos objetos, ao degustar um bolinho, que remete diretamente à infância ou pelas sensações de uma música, por exemplo. A narrativa ocorre por meio da primeira pessoa, evidenciando todo o percurso realizado até finalmente encontrar a verdade. Já para o outro, as experiências do passado não trazem a verdade, pois estão mergulhadas nos sentimentos e, desta forma, encontram-se deturpadas para melhor ou para pior.

\section{Considerações finais}

Duhamel em sua obra Remarques sur les mémoires imaginaires evidencia sua estratégia de criação literária ao denominar suas memórias de memórias imaginárias, nada mais sendo que o romance como é conhecido, com elementos ficcionais. No entanto, ele utiliza esse recurso como forma de manifestar e defender seu ponto de vista em uma época de reverberação dos movimentos vanguardistas. Para ele estes movimentos trouxeram consequências negativas para a literatura, como por exemplo, narrativas que exaltavam a realidade crua e pura dos fatos sem o menor cuidado estético.

Além de criticar os autores desta prática ele reflete sobre o processo de criação literária, que em determinados pontos assemelha-se à obra de Proust no que concerne a busca pela verdade. Entretanto, a busca pela verdade para Proust está ligada ao passado, por meio de sua trajetória e aprendizado, já para Duhamel a verdade não se limita aos fatos passados, mas requer um esforço para ser encontrada. Essa busca estaria vinculada à recriação do real, pois este cenário traria uma visão mais ampla dos acontecimentos e, assim uma visão mais completa e mais aproximada da verdade humana, sendo que esta deve ser universal e não particular.

Ainda para Duhamel, o processo de criação de memórias de um outro exige o afastamento de si: "Eu devo, várias vezes por dia, renunciar a mim mesmo, para trocar a luminosidade dos objetos, a incidência e a intensidade da luz, o horizonte, o ângulo visual"10 (tradução nossa). Este afastar-se de si revela esta ação de compreender as coisas além das experiências particulares e, deste modo transcendê-las para o nível comum a todos.

\footnotetext{
${ }^{10}$ « Il me faut, plusieurs fois par jour, renoncer à moi-même, pour changer l'éclairage des objets, l'incidence et l'intensité de la lumière, l'horizon, l'angle visuel » (DUHAMEL, 1934, p.60).
} 
Ao trilhar o caminho da criação literária, o autor de Remarques sur les mémoires conclui que a matéria-prima para um bom romance é o trabalho com os aspectos do eterno, algo que mesmo não sendo novidade, seja perene e universal.

É preciso recolher o eterno na poeira e depois elevá-lo ao céu. Esta não é uma tarefa fácil, pois o eterno às vezes se parece com o perecível. Os grandes artistas, se eles nos ganham, é pelo gosto da novidade? Não! É através da sua contribuição para o tesouro eterno ${ }^{11}$ (tradução nossa)

Assim o autor descobre, por meio de sua trajetória literária, aspectos que para ele são importantes e ao escrever esta pequena obra tem o desejo, sobretudo, de discutir e revelar suas ideias, fruto de sua experiência com romances cujas memórias são de um outro, como é o caso de Vie et Aventures de Salavin (1927) e, que por justamente serem criadas, recriam o real aproximando-se da verdade humana.

\section{Referências bibliográficas}

Académie française: Georges Duhamel. Disponível em <http://www.academiefrancaise.fr/les-immortels/georges-duhamel>. Acesso em 18 agosto 2017.

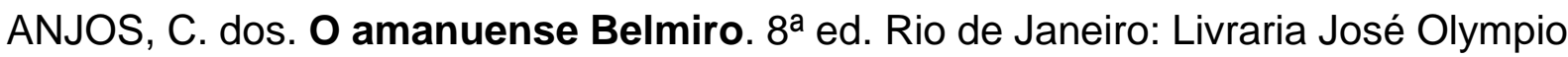
Editora, 1975.

CANDIDO, A.; ROSENFELD, A.; PRADO, D. de A.; SALLES G., Paulo E. A personagem de ficção. São Paulo: Perspectiva, Coleção Debates, 1995.

DELEUZE, G. Proust e os signos. Trad. Antonio Carlos Piquet e Roberto Machado. Rio de Janeiro: Forense-Universitária, 1987.

DENIS, B. Literatura e engajamento de Pascal a Sartre. Trad. Luiz Dagobert de Aguirra Roncari, Bauru: EDUSC, 2002.

DUHAMEL, G. Remarques sur les mémoires imaginaires. Paris: Mercure de France, 1934.

LEJEUNE, P. Le pacte autobiographique. Paris : Seuil, 1975.

SANTIAGO, S. A vida como literatura: 0 amanuense Belmiro. Belo Horizonte: Editora UFMG, 2006.

\footnotetext{
${ }^{11}$ «Il faut ramasser l'éternel dans la poussière et puis l'élever au ciel. Ce n'est pas une quête aisée, car l'éternel, parfois, ressemble au périssable. Les grands artistes, s'ils nous gagnent, est-ce par le goût de nouveauté ? Que non! C'est par leur contribuition au trésor d'éternel » (DUHAMEL, 1934, p.52).
} 
TIEGHEM, P. Van. Petite Histoire des grandes doctrines littéraires em France. Paris: Presses Universitaire de France, 1957.

PROUST, M. Du côté de chez Swann. Paris: éditions de la nouvelle revue française, 1919. 